\title{
Remote Sensing of Irrigated Agriculture: Opportunities and Challenges
}

\author{
Mutlu Ozdogan *, Yang Yang, George Allez and Chelsea Cervantes \\ Center for Sustainability and the Global Environment (SAGE), University of Wisconsin-Madison, \\ 1710 University Avenue, Madison, WI 53726, USA; E-Mails: yyang72@wisc.edu (Y.Y.); \\ nikallez@chorus.net (G.A.); cervantes@wisc.edu (C.C.)
}

* Author to whom correspondence should be addressed; E-Mail: ozdogan@wisc.edu.

Received: 29 July 2010; in revised form: 15 September 2010 / Accepted: 25 September 2010 / Published: 27 September 2010

\begin{abstract}
Over the last several decades, remote sensing has emerged as an effective tool to monitor irrigated lands over a variety of climatic conditions and locations. The objective of this review, which summarizes the methods and the results of existing remote sensing studies, is to synthesize principle findings and assess the state of the art. We take a taxonomic approach to group studies based on location, scale, inputs, and methods, in an effort to categorize different approaches within a logical framework. We seek to evaluate the ability of remote sensing to provide synoptic and timely coverage of irrigated lands in several spectral regions. We also investigate the value of archived data that enable comparison of images through time. This overview of the studies to date indicates that remote sensing-based monitoring of irrigation is at an intermediate stage of development at local scales. For instance, there is overwhelming consensus on the efficacy of vegetation indices in identifying irrigated fields. Also, single date imagery, acquired at peak growing season, may suffice to identify irrigated lands, although to multi-date image data are necessary for improved classification and to distinguish different crop types. At local scales, the mapping of irrigated lands with remote sensing is also strongly affected by the timing of image acquisition and the number of images used. At the regional and global scales, on the other hand, remote sensing has not been fully operational, as methods that work in one place and time are not necessarily transferable to other locations and periods. Thus, at larger scales, more work is required to indentify the best spectral indices, best time periods, and best classification methods under different climatological and cultural environments. Existing studies at regional scales also establish the fact that both remote sensing and national statistical approaches require further refinement with a substantial
\end{abstract}


investment of time and resources for ground-truthing. An additional challenge in mapping irrigation across large areas occurs in fragmented landscapes with small irrigated and cultivated fields, where the spatial scale of observations is pitted against the need for high frequency temporal acquisitions. Finally, this review identifies passive and active microwave observations, advanced image classification methods, and data fusion including optical and radar sensors or with information from sources with multiple spatial and temporal characteristics as key areas where additional research is needed.

Keywords: irrigation; agriculture; remote sensing; image classification; resolution

\section{Introduction}

The intensification of agricultural practices - under the auspices of the "Green Revolution" that includes better seeds, extensive fertilizer use, and irrigation—-has dramatically altered the relationship between humans and environmental systems across the world. Today many agricultural lands are being used much more intensively as opportunities for expansion are being exhausted elsewhere. In the last 40 years, global agricultural production has more than doubled—although cropland has increased by only $12 \%$ - in part through increased reliance on irrigation [1,2]. Currently, irrigated agriculture is the principal consumer of fresh water resources; it accounts for more than 70 percent of water withdrawn from lakes, rivers, and groundwater aquifers [3]. As the earth's population continues to increase and the demand for food, fuel, and fiber rises, continued agricultural intensification will require at least a 50 percent increase in water resources, especially in arid and semi-arid regions [4].

While these modern agricultural practices have successfully increased food production, they have also caused significant environmental change in many regions. Accurate information on the extent of irrigation is thus fundamental to many aspects of Earth System Science, and global change research in general. These aspects include modeling of water exchange between the land surface and atmosphere [5-8], analysis of the impact of climate change and variability on irrigation water requirements and supply [9-13], management of water resources that affect global food security [14], and climatic feedbacks, including the effect that results from evaporative cooling in intensely irrigated arid areas $[15,16]$.

Despite their significance for food security and the water and energy cycles, the extent and distribution of irrigated areas worldwide still remain uncertain [17]. Existing maps, especially those covering large areas, have been derived primarily from country-level statistics. The politically charged nature of irrigation often sets the stage for under-reporting of water use; this is especially true in countries that share resources across borders with their neighbors [18]. Country-level estimates also mask the considerable spatial variability in irrigation practices, and simply cannot reflect the location or extent of irrigation across large areas [19]. Even in countries such as the U.S., where the extent of irrigated areas is known, irrigation-related information exists in disparate sources and cannot be easily synthesized into a single continental scale database [20]. Also, information on irrigated areas in many countries is reported only from officially recognized management units (or command areas) serviced 
by large scale irrigation projects. As a result, subsistence-scale irrigation is not reported, although these areas could collectively account for a substantial land area and significant amount of water use.

Satellite remote sensing offers tremendous potential for routine monitoring of irrigation due to the synoptic nature of the data and readily available archives of imagery. Yet studies that have used remote sensing to map irrigated lands remain relatively rare. This is a direct result of the complexity associated with trying to map land use as opposed to land cover. While it may be straightforward to detect the high near-infrared signal of mature crops given appropriate spatial, spectral and temporal resolution data (i.e., land cover), detecting irrigation requires knowledge of land management, or some understanding of where and when humans have provided water or supplemented rain-fed crops (i.e., land use). Because of the difficulty in isolating these practices with satellite observations, a literature search reveals only 65 peer-reviewed papers that use remote sensing to map irrigation, compared to thousands that report agricultural or land-cover mapping activities. Thus, from the remote sensing perspective, studies that attempt to map irrigated areas have been rare and scientific consensus on mapping methodologies is fragmented and evolving.

This review seeks to synthesize current studies on identification and mapping of irrigated areas by remote sensing. Our goal is two-fold. First, we will provide a reference guide to the spatial, spectral, and temporal information requirements for monitoring irrigated areas, derived from case studies that have successfully mapped irrigated lands. Second, and more important, we will establish the state-of-the-art in this field by providing a comprehensive assessment and a taxonomic synthesis of studies to date. This information can provide a foundation for future studies to expand on these methods and fill data gaps. The approaches that have been adopted to tackle irrigation are diverse; they vary in scale, extent, data inputs and processing requirements. It is also clear that a consensus within the scientific community as to the 'best practices' for mapping irrigation are still evolving, although certain methods appear to be common among different studies. Moreover, reviews such as this portray information needs for timely and accurate monitoring of irrigation. This is necessary in order to form the basis for development of sustainable water management practices within the context of what is perhaps the greatest human intervention in the hydrological cycle.

\section{Advantages and disadvantages of remote sensing}

We will begin with a brief discussion of the benefits and drawbacks of remote sensing for mapping crop location, productivity, and change in irrigated settings. Remote sensing has been an effective tool to monitor irrigated lands in many locations around the world under a variety of environmental conditions [19-21,28,33,35,50,60,65]. It provides synoptic coverage of irrigated fields in several spectral regions and with temporal frequencies sufficient to assess vegetation growth, maturity, and harvest. Archived data that span many years allow comparison of images, thus revealing change. The digital nature of satellite data also makes it relatively easy to integrate into a Geographic Information System (GIS) for synthesis or comparison with other data sources. Remotely sensed data are also less costly and time-consuming than traditional statistical surveys that may require aerial photography over large areas. This makes remote sensing particularly valuable for inventories of irrigated land and for monitoring in developing countries, where funds are limited and little objective information is available. Moreover, remote sensing delivers useful spatial information on the exact locations of 
irrigated lands rather than mere totals within arbitrary political units. This is important for prioritizing water delivery, assessing irrigation performance, providing irrigation intensities (e.g., single crop vs. double crop), quantifying environmental impact, objectively assessing irrigation water use and understanding changes where irrigation occurs. Finally, remote sensing can provide information on timing, both in the number of irrigation-related vegetation peaks and in the length of time irrigation is utilized over the course of a year.

However, satellite imagery also has limitations. Because of the spatial resolution of most operational imagery $(15-60 \mathrm{~m})$, it is difficult to identify small irrigated areas which, taken together, may cover significant parts of the earth. It is also difficult to separate irrigated fields from non-irrigated plots in humid areas because of substantial overlap in their spectral signatures. For example, the signatures of flooded irrigated fields at certain growth stages may overlap with those of natural wetlands, thus limiting accuracy in mapping. Researchers have overcome these limitations by using temporal information on crop planting, maturity, and harvest in conjunction with spectral information [21]. Unfortunately, the collection of remotely-sensed data is fixed by a given satellite's orbit and return interval, and thus observations are not always captured at ideal times (e.g., green-up or harvest). Optical data availability is also problematic in areas with frequent cloud cover, such as humid tropical and sub-tropical environments.

Having stated this, it is important to point out the technological advances made in remote sensing. For example, satellite constellations such as Rapideye with 5 meter spatial resolution and providing data in five spectral bands has already covered nearly 95\% of USA geographic area in less than one year after launch. Further, multi-sensor data fusion (e.g., IRS, Rapideye, Landsat) are becoming increasingly important and feasible. Finally, looking at the limitations of conventional datasets such as subjectivity in data collection and varying statistical design in different studies, limitations from remote sensing by itself are less certain.

The final limitation considered here comes from the fact that identification of agricultural fields using remote sensing is difficult because irrigated landscapes are a subclass of croplands that themselves have traditionally been difficult to map [22-24]. Agricultural fields (and especially irrigated fields) are highly dynamic because each field may be at a different stage of development, and thus subject to being confused with natural land cover classes. Accuracy of land-cover maps is often inversely related to their categorical detail. Since agriculture is already inherently difficult to identify and map, the task of identifying irrigated areas as a subclass of cultivation becomes even more difficult. Perhaps this is where temporal data profiles will be invaluable to separate irrigation from rainfed agriculture as successfully demonstrated by [21,61]. Moreover, ancillary datasets on precipitation and evapotranspiration will come in handy when interpreting these temporal profiles [20].

\section{Definition of irrigation}

If we are to identify and map irrigation with remote sensing, a precise definition of what is considered to be irrigated is needed. In this review, we define irrigated lands as areas that receive full or partial application of water by artificial means to offset periods of precipitation shortfalls during the growing period. Fully irrigated areas are those where more than 60 percent of crop water requirements are met artificially; partially irrigated lands (or supplementally irrigated areas) receive between 30 and 
60 percent artificially. Note that both surface and groundwater deliveries are included in this definition provided human intervention to move water from one location to another is involved.

Irrigation is practiced in virtually every country, at scales ranging from subsistence farming to national enterprise. The precise location is determined by a combination of factors that include climate, resource availability, crop patterns, and technical expertise. Climate plays an important role in the distribution of irrigation as it determines natural moisture availability (precipitation), crop demand (evaporation), and crop schedules. In humid climates, irrigation often takes the form of a supplemental water supply to meet the excess demand of crops whose growth cycle may be out of sync with natural precipitation. In arid and semi-arid climates, continual irrigation is often necessary to assure agricultural production.

While climate is an important driver of the need for irrigation, it is water availability that primarily determines its existence and sustainability. Currently, groundwater is by far the greater source for irrigation [25]. In regions where withdrawals for agriculture exceed recharge rates, the quantity and quality of groundwater quickly deteriorates, jeopardizing its sustainability. Thus nations may be forced to decide between agricultural and domestic use in their allocation of groundwater. Surface water for irrigation purposes appears more sustainable, but this is deceptive. It requires large structures involving complex engineering such as dams, conveyers, and canals to redistribute the resources. Furthermore, most river basins span international boundaries. Diversions of water for irrigation upstream often reduce its availability downstream, leading to international conflicts as in the case in the Middle East and Central Asia.

\section{Review of Existing Studies}

In this section, we review existing studies on irrigation mapping with remote sensing and assess data and methodological features that are common and practical. We have chosen spatial scale to categorize these studies. Here spatial scale identifies the scope of the study area and is defined as local, regional, or global. Local studies refer to one or more irrigation basins or command areas. Regional studies include large river basins and continental areas, while global studies present attempts to map irrigation worldwide. This conceptual framework is helpful both to understand the processes involved in each category and to classify mapping approaches. Within each category, the discussion is further organized around the nature of remote sensing imagery and methods of processing these images. In tabular format we describe the advantages and disadvantages of satellite sensors that have been used to identify and map irrigated lands for the following imaging systems: Landsat, Satellite Pour l'Observation de la Terre (SPOT), China-Brazil Earth Resources Satellite (CBERS), Advanced Very High Resolution Radiometer (AVHRR), Moderate Resolution Imaging Spectroradiometer (MODIS), Medium Resolution Imaging Spectrometer (MERIS), and Indian Remote Sensing Satellite (IRS) (Table 1). Finally, we provide selected examples from the literature for image classification techniques to determine the most successful options in identifying irrigated areas and separating them from other land cover types (Table 2). The accuracy of these classifications is included to give an idea of each method's success. 
Table 1. Current operational optical sensors and their technical/logistical capacities for irrigation mapping. Some of the table headings are adapted from the United Nations Collaborative Programme on Reducing Emissions from Deforestation (UN-REDD) sourcebook and Forest Degradation in Developing Countries [97].

\begin{tabular}{|c|c|c|c|c|c|c|c|}
\hline $\begin{array}{l}\text { Satellite } \\
\text { observation } \\
\text { system/prog } \\
\text { ram }\end{array}$ & $\begin{array}{l}\text { Technical } \\
\text { observation } \\
\text { challenges } \\
\text { solved }\end{array}$ & $\begin{array}{l}\text { Access to } \\
\text { information/ } \\
\text { data } \\
\text { worldwide }\end{array}$ & $\begin{array}{l}\text { Continuous } \\
\text { observation } \\
\text { program with } \\
\text { global } \\
\text { coverage }\end{array}$ & $\begin{array}{l}\text { Pre- } \\
\text { processed } \\
\text { datasets } \\
\text { accessible }\end{array}$ & $\begin{array}{l}\text { Image } \\
\text { data } \\
\text { cost }\end{array}$ & $\begin{array}{l}\text { Technical } \\
\text { difficulty } \\
\text { required to } \\
\text { produce } \\
\text { maps }\end{array}$ & $\begin{array}{l}\text { Frequency of } \\
\text { use in } \\
\text { irrigation } \\
\text { studies }\end{array}$ \\
\hline RapidEYE & yes & no & yes & yes & high & medium & low \\
\hline Landsat & yes & yes & yes & yes & low & medium & high \\
\hline SPOT & yes & yes & yes & yes & high & medium & medium \\
\hline AWiFS & yes & no & no & yes & high & medium & low \\
\hline LISS & yes & no & no & yes & high & medium & low \\
\hline ASTER & yes & yes & no & yes & low & medium & low \\
\hline CBERS & no & no & no & no & low & medium & low \\
\hline THEOS & yes & no & no & yes & medium & medium & low \\
\hline MODIS & yes & yes & yes & yes & low & high & medium \\
\hline MERIS & yes & yes & yes & yes & low & high & low \\
\hline AVHRR & yes & yes & yes & yes & low & high & medium \\
\hline SPOT VEG. & yes & no/yes & yes & maybe & low & medium & low \\
\hline
\end{tabular}

Table 2. Summary of spatial scales, sensors, methods, and example applications in the literature.

\begin{tabular}{llll}
\hline Spatial scale & Sensors used & Method of mapping & References \\
\hline local & Landsat TM/ETM+, SPOT, & Photo interpretation, Image arithmetic, & {$[26-29,31-33$,} \\
& LISS, ASTER, AWiFS, & Image classification, segmentation, & $42-44,98]$ \\
\multirow{4}{*}{ regional } & CBERS, THEOS & image fusion & \\
& Landsat TM/ETM+,MODIS, & Times-series analysis, & [21,47-50,53] \\
& MERIS, AVHRR, SPOT VGT & Supervised/unsupervised classification, & \\
& & masking & \\
continental & Landsat TM/ETM+, MODIS, & Times-series analysis with other & {$[7,19-21,49$,} \\
& MERIS, AVHRR, SPOT VGT & ancillary data, data fusion & $52,98]$ \\
global & MODIS, MERIS, AVHRR, & Unsupervised clustering, machine & {$[22,54-57]$} \\
& SPOT VGT & learning algorithms applied to time- & \\
& & series data, also employ other ancillary & \\
& & data(statistic, ground truth data...) & \\
\hline
\end{tabular}

\subsection{Local Scale Studies}

To date, most research on remote sensing-based irrigation mapping occurs at local scales for several reasons. First, local areas provide familiar environments where investigators have extensive knowledge of their study sites. Second, the purpose of a remote sensing study may be to demonstrate the utility of a method rather than an operational assessment encompassing all irrigation. In these cases a small area suffices. Third, irrigation practices take many forms and this variation increases as the 
study area becomes larger. Therefore methods developed in one place and time may not be appropriate for other locations and durations.

Two forms of mapping methods emerge as most common in local area studies. These methods are visual interpretation and digital image classification. Early work concentrated on determining the utility of remotely sensed imagery using various visual interpretation techniques adapted from the airphoto sector to map and update irrigated acreage, mainly in the U.S. and India [26-32]. More recent studies have developed digital image classification methods specifically adapted to mapping irrigated lands automatically [33-37]. Within each category, several methods have been tested.

\section{Visual interpretation of satellite imagery}

Early work with satellite imagery at the local scale relied on visual interpretation of large hard-copy satellite image prints to identify and map irrigated lands [26-28]. These investigations recognized that satellite data provided a cost-effective method of obtaining multiple images during the growing season, an important consideration for identifying irrigation. Initially, traditional photo interpretation methods were used on Landsat color composite images from multiple dates to draw boundaries of irrigated fields by hand. For visual interpretation, particular attributes of satellite data that proved useful were spectral availability in several channels including near-infrared, and temporal availability of imagery at low cost. Archival image data from multiple years also proved useful because newly irrigated croplands showed a color signature distinct from those previously irrigated. Since manual interpretation of satellite images is performed by an analyst, it is possible to use shapes of irrigated fields as an additional feature for identification [32]. Irrigated acreage inventories based on identifying and mapping the characteristic circular pivot system as seen in photographic enlargements of Landsat imagery are prime examples of these shape-based interpretation methods in the U.S. While this form of detection is simplistic, it provides an excellent example of the practical utility of remote sensing.

Visual interpretation of satellite data also includes automated approaches [29,30,38,39]. These studies benefit from the strong spectral separation of irrigated fields from harvested and fallow fields in the visible and near-infrared portions of the electromagnetic spectrum. One study [29] even demonstrated that in semiarid areas, croplands irrigated by surface water could be distinguished from those irrigated with ground water by visual interpretation of single-date Landsat imagery, although it was harder to identify different crop types.

Studies involving visual interpretation of satellite data also benefit from radiometric enhancements and manipulations in the form of spectral indices. Studies that compare these data to automated techniques of image classification report superior performance of manual mapping of area estimates when compared to reported acreage [30]. For example, by visually interpreting satellite imagery, Rao and Mohankumar [40] conducted an inventory of the cropland in a command area while evaluating various vegetation indices derived from Landsat-TM in India. The accuracy of the estimated irrigated crop area was within five percent of the estimate for the entire command area made by the Directorate of Economics and Statistics (DES) of the Indian government. Studies like this demonstrate that remote sensing is an effective time-saving technique to provide seasonal assessment of irrigated croplands and that the per hectare cost using remote sensing is often between one-half and one-fifth the cost of a conventional system based on air-photo interpretation supplemented by ground surveys. 
While considered simplistic by today's image processing standards, the early work with visual interpretation of satellite data established several facts that hold true today. First, visual interpretation by analysts is by far the most accurate method of mapping land cover, irrigation included. This is because the human brain and expertise are the best image processors. However, visual interpretation can be expensive, although it is less costly than traditional air photo interpretations of large areas. Second, the red and the NIR portions of the electromagnetic spectrum provide tremendous information for recognizing irrigation. Third, multiple images during a single growing season increase accuracy because of differential growth stage times. Finally, while irrigation identification is possible with visual interpretation, identification of crop types is less reliable unless multiple images are available from the same growing season.

\section{Digital image classification}

Although visual interpretation of satellite images is useful, more recent work has emphasized digital image classification, partly because the analysis times are shorter and costs associated with mapping are lower. Common methods include multi-stage classification [31,41], unsupervised clustering [31,33,42], density slicing with thresholds [7,43,44], and decision tree classifications [45].

The multi-stage approach involves identification of land cover at increasingly refined categorical levels following the concept that irrigated areas are a subclass of cultivated lands, which themselves belong to vegetated landscapes. As noted, the accuracy of land-cover maps is often inversely related to their categorical detail. Thus, categorizing the landscape at each stage into more refined classes enables better identification of irrigated areas as a subclass.

As in visual interpretation, digital image classification benefits from spectral transformations [7,33,35,42,44]. In particular, the Normalized Difference Vegetation Index (NDVI) proves to be indispensible for identifying irrigated areas in local scale studies, in part because of differential spectral response between irrigated and non-irrigated fields. Common use of NDVI would include direct insertion into a classification algorithm as an input feature. Thresholds are set to distinguish productive fields from non-productive and non-irrigated areas, and also multi-temporal NDVI features such as the range and maximum NDVI. When multiple NDVI observations are available from the same growing season for several years, it is also possible to identify crop types as well as the changes in irrigated areas.

Multi-temporal data availability has also proved to be very useful in identifying irrigated areas. When using data from multiple time periods, the discrimination procedure is based on the different spectral responses of crops according to their phenological evolution. A number of studies have demonstrated that using spectral information from two consecutive seasons in a crop-year is sufficient to identify the irrigated crops, especially when only a few are dominant. However, for each season, the estimates require multiple images [36]. This is because single-date analysis in visible cropping intensity often does not take into account planting dates that vary from year to year. Therefore, multi-temporal analysis has greater potential to define irrigated areas [46]. Ultimately, classification results are conditional upon the temporal and spatial variability of the spectral signature of the land cover type in question, so suitable images must be available for the temporal approach to provide a complete inventory of all irrigated fields in a study area. 
It is also possible to map irrigation with a single image during the peak irrigation season as long as its peak can be identified using a time-series of observations. One technique is to use coarse spatial resolution time series data to select the ideal time period where irrigation information is maximized and then acquire high resolution data to do the actual mapping at local and regional scales [7].

The review of local scale studies suggests that both methods baed on both visual intepretation and statistical and non-parametric classifications of image data work equally well in identifying irrigated areas. In general accuracies better tht 85 percent hav been achived with both approaches. In terms of spectral bands of importance, near-infrared combined with at least one visible light containing band have consistently produced higher classification accuracies than mapping applications that do not include these bands. It is also possible to map irrigation using single image NDVI data as long as the study area contains only a few classes to be distinguished. For example, these forms of classifications were more successful in mono cropped areas like the US mid-west when compared with fragmented irrigated landscapes of Asia and were quite futile in highly mixed cropping in Africa.

These studies also indicate that multi-temporal satellite remote sensing is a viable approach for identifying and monitoring irrigation. Methods based on multi-temporal NDVI features derived from Landsat data were particularly successful in distinguishing healthy irrigated lands from uncultivated and nonproductive areas.

\subsection{Regional Studies}

The most common method of mapping irrigated areas at regional scales is to use medium to coarse spatial resolution data from many time periods in the form of time series analysis. The image-based monitoring in the time domain relies heavily on the monitoring of crop evolution during the growing season by means of original spectral bands or vegetation indices. This requires knowledge of the growth schedules of crop types common to the area.

One of the most cost effective ways of monitoring irrigation in large areas is to use freely available vegetation index data from coarse resolution sensors like AVHRR and MODIS [19,21,47-52]. There are various ways to translate multi-temporal information to a map of irrigation. For example, Xiao et al. [48] developed a paddy rice mapping algorithm that uses time series of three vegetation indices, namely the Land Surface Water Index (LSWI), the Enhanced Vegetation Index (EVI) and NDVI, derived from MODIS images. This method relies on identification of the initial period of flooding and transplanting in paddy rice fields by exploiting the sensitivity of LSWI to the increased surface moisture during this period

It is also possible to use the results of multi-temporal vegetation indices directly in modern classification algorithms such as decision trees [20,49,51]. Classification accuracies in such applications range from 60 percent to better than 90 percent [20,21,48,51]. Notable regional differences in irrigated areas estimated this way stem from climate factors, localized precipitation patterns, and specific cropping practices [51]. Moreover, this form of classification benefits greatly from a multi-stage approach where the land cover is progressively classified [51] and from using ancillary information on climate, surface moisture status, elevation, natural land cover cartography, and crop area and water masks [20,21,53].

There are indications that multi-temporal image classification using the original spectral bands in addition to the band transformations leads to better classification results when satellite data with high 
temporal and spectral dimensionality such as MODIS are used [21,52]. For example, Thenkabail et al. [21] developed innovative approaches to obtain precise information on the onset, peak, senescence and duration of each irrigated and rainfed land use class. In particular, their results demonstrated that the value of the MODIS band 5 centered at 1,240 nm provided the best separability, followed by bands 2 (859 nm), 7 (2,130 nm), 6 (1,640 nm) and $3(648 \mathrm{~nm})$.

Algorithms that can automatically identify the location and the number of vegetation peaks in a time series plot improve classification accuracies. For example, Kamthonkiat et al. [53] developed a Peak Detector Algorithm to identify the number of vegetative peaks based on time lag between peak rainfall and peak NDVI. Their results indicate that in rainfed rice there is high correlation at a 40-50 day lag between peak rainfall and a single peak NDVI, while in irrigated rice there are multiple peaks and multiple correlations with low values for at least 90 days after peak rainfall.

One of the limitations of time series analysis of coarse spatial resolution data is the imprecise irrigated area estimates, especially in locations with small cultivated plots and fragmented landscapes. In these types of environments, remotely sensed estimates are generally higher than reported estimates because of: (a) inadequate accounting of irrigated areas in reported statistics, especially minor forms of irrigation; (b) definition issues involved in mapping using both remote sensing and statistics; (c) difficulties in arriving at precise estimates of irrigated area fractions; and (d) imagery resolution [19-21,52].

One approach to overcome these issues is to use high spatial resolution data such as Landsat to calibrate irrigated area from coarse resolution observations using regression [46,49]. Results from these calibration-based approaches to area correction suggest that while calibration seems to work well for homogeneous areas, for heterogeneous areas, where irrigated fields are scattered against a predominantly non-vegetated background, coarse resolution vegetation index values become rather low and consequently the regression relations are less reliable. However, comparison of multiple data sources improves confidence in the classification and identifies areas requiring more intensive fieldwork [49]. Another approach directly from the remotely sensed observations is to use a regression algorithm to derive the fraction of irrigated area within each pixel that had been identified as having irrigation [20]. However, both approaches establish the fact that both remote sensing and national statistical approaches require further refinement with a substantial investment of time and resources for ground-truthing.

\subsection{Global Studies}

In recent years, there have been several attempts to determine the spatial extent of irrigation at global scales. These attempts stem particularly from the crucial need for accurate estimates of irrigated areas for water use assessments and food security studies. One such attempt is the USGS Global Land Cover Map [22] that was generated based on 1km AVHRR observations between April 1992 and September 1993. Among several land-cover legends that the database contains, the Global Ecosystems Legend identifies four irrigated classes: irrigated grasslands, rice paddies and fields, hot irrigated cropland and cool irrigated cropland. When combined, these classes provide one of the few sources of remotely-sensed information on spatial distribution at the global scale. The major shortcoming of the USGS map, however, is that irrigated areas were determined as part of a broader classification scheme. Thus the emphasis was primarily on other land-cover types while irrigated classes received less attention and thus lower classification accuracy. Vörösmarty and Sahagian [14] compared irrigated 
lands depicted by the USGS map to the country level reports of irrigated areas [54] and pointed to major uncertainties in classification and inventory due to the highly politicized nature of FAO data reports, as well as to the technical limitations of the more objective datasets made from remote sensing.

More recently, the European Space Agency (ESA) produced a moderate spatial resolution (300 m) global land cover product (GlobeCover) using Medium Resolution Imaging Spectrometer (MERIS) data acquired between mid-2005 and mid-2006 [55]. Several thematic classes within the GlobeCover legend identify irrigated crops, including flooded rice. The classification process includes unsupervised clustering of selected mosaics that are then temporally characterized based on computation of phenological parameters (start, end and duration of the vegetation period), using the time series of MERIS mosaics. In the last step, the classes were labeled with help from regional land cover experts, who advised on the interpretation of the spectral-temporal classes, and defined the improved labeling rules.

Thenkabail et al. [56] evaluated the utility of spectral matching techniques to determine historical land use and land cover (LULC) and irrigated area classes using the historical time series 0.1-degree AVHRR data without ground truth comparison. By using monthly continuous time series AVHRR data, they established the LULC for the period 1982-1985 and for the period 1996-1999. They used quantitative and qualitative spectral matching methods to identify and label LULC classes, including spectral similarity value, spectral correlation similarity, Euclidian distance, and modified spectral angle. The results show that spectral similarity was the best method, followed by spectral correlation. The other methods were more complex, and provided results that were either uncertain or no better. They used data from India's Central Board of Irrigation and Power for validation. The 1982-1985 irrigated area was 2,975,800 hectares, which was 8.5 percent higher than the non-remote-sensing-based area estimate by the Central Board for 1984 (2,743,638 hectares). These results helped establish the strengths of the spectral matching techniques in identifying and labeling LULC and irrigated area classes from the historical satellite sensor data for which little or no ground truth data are available. The spectral matching methods can be further strengthened by additional research involving a rich ground-based knowledge base. The study also implied that future application of this method at global scale is promising but may require a better potential irrigation index and the use of remotely-sensed skin temperature measurements.

Thenkabail et al. [57] also produced a Global Irrigated Area Map (GIAM) for the end of the last millennium. They used multiple satellite sensor and ancillary data including AVHRR 3 band and NDVI; SPOT VGT NDVI; monthly rainfall and temperature; elevation; Japanese Earth Resources Satellite-1 Synthetic Aperture Radar (JERS-1 SAR) data for the rain forests; and a map of global tree cover. In the first phase, the global land surfaces were segmented based on elevation, temperature and precipitation zones. Next, classification was performed within these segments using class spectra derived from unsupervised classification; these were matched with ideal or target spectra. Finally, the mixed classes were resolved based on decision tree algorithms and spatial modeling. Whenever that did not work, the problem class was used to mask and re-classify the original input data and the class identification and labeling protocol was repeated. The sub-pixel area calculations were performed by multiplying full-pixel areas with irrigated area fractions for every class. 
The most important property of this methodology is that it delineates areas most likely to be rainfed. Such mapping is essential in the entire classification process as it can be overlaid with a map of green areas and only the non-rainfed green areas can then be considered to be irrigated. The methodology described here to create a map of Potentially Irrigated Areas (PIA) is based on Droogers and Aerts [10].

\section{Emerging Patterns from Existing Studies}

\section{Spatial resolution requirements}

Irrigation is practiced in many forms around the world and the spatial resolution requirements go hand in hand with its heterogeneous distribution. Figure $1(\mathrm{~A}-\mathrm{C})$ shows ground level photographs of several landscapes from very heterogeneous small plot sizes in SE Asia to vast expanses of irrigated fields in the U.S. The purpose of these pictures is to illustrate the great variation in irrigation presence from subsistence farming to major enterprises. This diversity directly affects our ability to map irrigation with remote sensing. In general, to map irrigated croplands accurately, the spatial resolution of the sensor should be at or below the size of the fields of interest. However, enhanced information brought about by high spatial resolution data does not tell the whole story-automatic identification of irrigated lands also relies heavily on temporal availability of information. If the low spatial resolution option is chosen, then frequent observations are available, but the low resolving power of pixels would lead to the mixed pixel problem. Consider a single AVHRR $10 \mathrm{~km}$ pixel, which encompasses an area of 10,000 hectares, while a MODIS 500 meter pixel covers 25 hectares. Obviously in many cases only a fraction of a coarse resolution pixel falls in a particular land cover category, such as irrigation. We also know that spatial resolution of a sensor is supply driven, that is, spatial resolution is fixed because of sensor design and flight characteristics.

Research has shown that the finer the spatial resolution, the greater the accuracy of irrigated area class designations [7,58]. For example, a recent study of the irrigated areas of the Ogallala Aquifer in the United States based on Landsat imagery and 364 ground truth points has shown that 18.5 percent of the areas actually irrigated were not included (errors of omission) in the GIAM dataset at $10 \mathrm{~km}$ resolution but 20.4 percent of the non-irrigated areas were included as irrigated areas (errors of commission) [59]. The reason for the errors of omission was that at coarser resolutions, smaller, more fragmented patches of irrigated croplands could not be delineated. In contrast, the errors of commission resulted because the large pixel sizes of coarse resolutions can at times map patchy non-irrigated areas that surround irrigated areas as if they too were irrigated. In either case, the need for finer spatial resolution is essential to resolve the confusion.

To overcome the mixed pixel issue present in low spatial resolution data, several researchers have developed schemes to "unmix" land cover classes—including irrigation-from the remotely sensed signal to estimate the sub-pixel areas of irrigated lands. Two approaches are common in the literature to estimate these irrigated area fractions. The first is a two-stage approach and determines the subpixel composition of a class label following initial categorical labeling with a classification algorithm [7,58]. For example, Thenkabail et al. [58] developed innovative methods to compute sub-pixel areas from coarse resolution data. They used the global GIAM dataset at $10 \mathrm{~km}$ resolution based on AVHRR data and the irrigated area map for India at $500 \mathrm{~m}$ based on MODIS data to test and verify their methods. 
The sub-pixel irrigated areas from coarse-resolution satellite sensor data were estimated by multiplying the full pixel irrigated areas with irrigated area fractions. The results indicated that the sub pixel areas provided significantly better correlation with the national statistics than full pixel areas, which were also shown to grossly overestimate reported areas.

Figure 1. Near ground photographs of irrigation practices in three different irrigated locations. (A) Irrigated rice paddies with a bore well in the background in north-central India. The complex nature of this landscape with multiple land cover types surrounding irrigated fields illustrates the need for high spatial resolution data which may come at a cost of frequency of observations needed to map paddy fields. Image is provided courtesy of Eby Heller from McGill University. (B) A large irrigated alfalfa field in Utah (USA) and a rotating drum irrigation system. In these types of environments, the spatial requirements for irrigation mapping can be relaxed but the spectral properties of the image signal must be enhanced to distinguish irrigation. Photo courtesy of USDA NRCS. (C) A large irrigated landscape interspersed with multiple land cover types in Idaho (USA). This photograph illustrates the fact that even though many landscapes may be heterogeneous, the size of individual landscape elements (e.g., cultivated fields) determines the spatial resolution requirements of an irrigation mapping exercise. Photo courtesy of USDA NRCS.

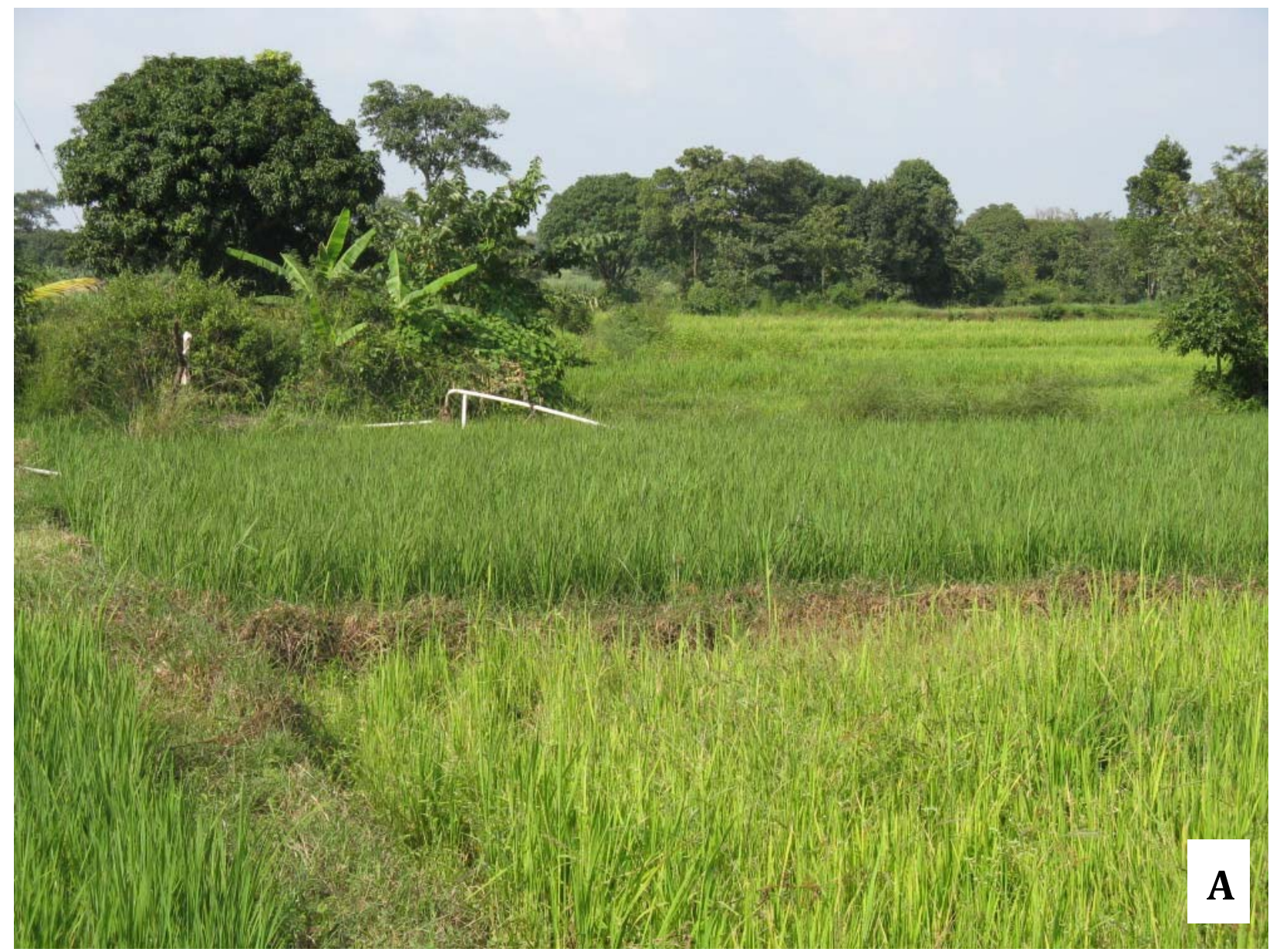


Figure 1. Cont.
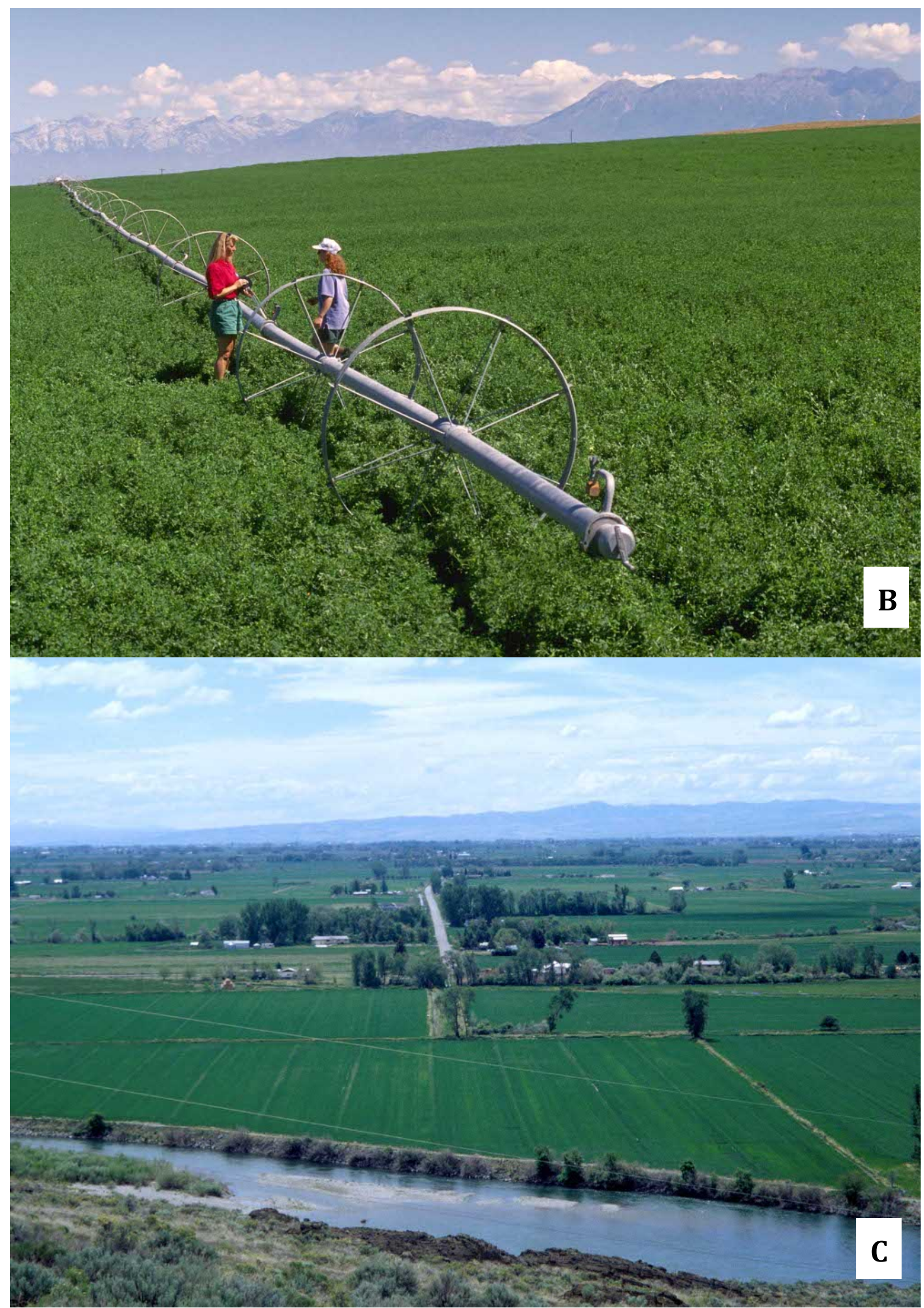
The second approach attempts to derive the information on subpixel composition of irrigated pixels directly from the remotely sensed signal using a pixel decomposition method. For example, the authors in [20,62] reported on the use of land surface temperature data, especially the diurnal difference (day vs. night) in land surface temperature, and how this may relate to irrigated area intensity. As an example, Figure 2 shows that as the difference between minimum and maximum land surface temperatures decreases, irrigated crop intensity increases due to increased modulation of radiative temperature by vegetation/moisture presence. This information can be used to directly map the intensity of irrigated areas using land surface temperature sensors at high observation frequencies.

Figure 2. The relationship between diurnal difference (day minus night) in land surface temperature and subpixel intensity of irrigated area at a location in western US as observed by MODIS. As the irrigation intensity increases, the modulating effect of evaporation and associated cooling of the land surface becomes more pronounced. This indicates that the land surface temperature difference data which is routinely available from remote sensing could be used to map fractional coverage of irrigation using coarse resolution sensors. Ozdogan unpublished data.

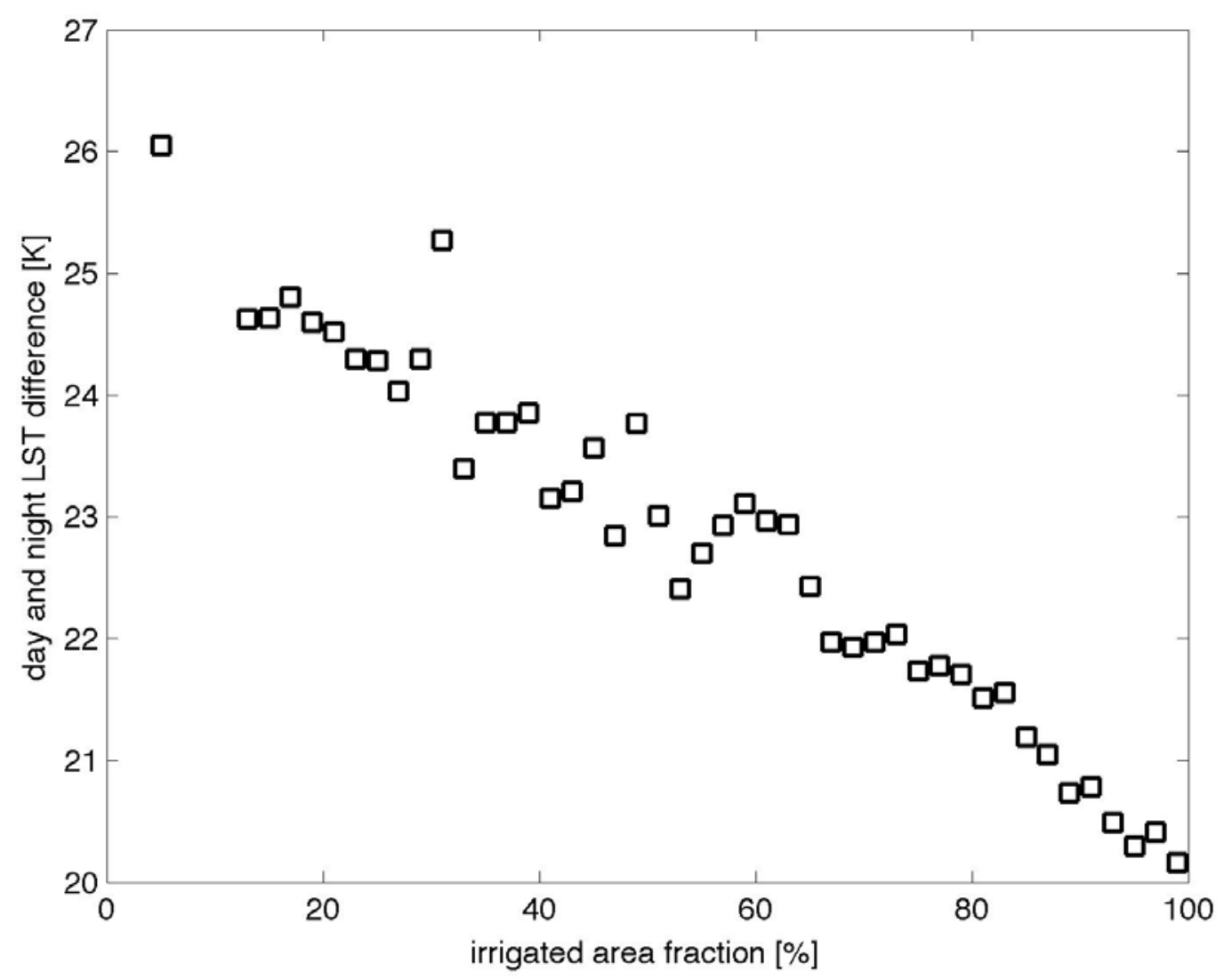

The spatial resolution dependent changes in irrigated area were also explored by Velpuri et al. [63] who determined how irrigated areas change with resolution (or scale) of imagery in the Krishna River basin in India. The irrigated areas were mapped using satellite sensor data at four resolutions: (a) AVHRR (10,000 m); (b) MODIS (500 m); (c) MODIS (250 m), and (d) Landsat (30 m). The proportion of irrigated areas relative to Landsat derived irrigation figures (9.36 million hectares for the Krishna basin) were (a) 95 percent using MODIS 250 meter data, (b) 93 percent using MODIS 
500 meter data, and (c) 86 percent using AVHRR at 10,000 meters. The study also found that the precise locations of the irrigated areas were better established using finer spatial resolution data. This study suggested that "the finer the spatial resolution of the sensor, the greater was the irrigated area," since at finer spatial resolutions fragmented areas are better detected. Accuracies and errors were established consistently across the four resolutions mentioned above for three classes: surface water irrigation, ground water/conjunctive use irrigation, and no irrigation. The results showed that Landsat data provided significantly higher overall accuracy (84 percent) when compared to MODIS $500 \mathrm{~m}$ (77 percent), MODIS $250 \mathrm{~m}$ (79 percent), and AVHRR 10,000 m (63 percent).

Even if the satellite sensor has sufficient spatial resolution to map irrigated areas in a particular location, the pre-processing of the sensor data may distort the original resolution. For example, Tan et al. [64] showed that gridding artifacts between satellite observations and predefined grid cells strongly influence the local spatial properties of MODIS images. The sensor observation in any grid cell is only partially derived from the location of the cell, with the average overlap between observations and their grid cells being less than 30 percent. This mismatch between grid cells and observations has important implications for the use of reference data for the validation of MODIS products or the training of MODIS algorithms. When generating multi-date composites, gridding artifacts also introduce bias when spectral compositing criteria are used. The band-to-band registration for the different spatial resolutions of gridded MODIS data can be poor if the different resolutions of data are gridded before aggregation. In all cases it is imprecise to characterize the subpixel properties of the coarser resolution bands using the finer resolution bands due to poor correspondence in the areas from which the observations are derived. All of the band-to-band registration problems are minimized when the MODIS data are aggregated to coarser resolutions. When validating algorithm accuracy, data on the observation dimensions and the offsets between the grid cell and the observation should be included to ensure the quality of validation results. If this information is not available, MODIS data should be aggregated to coarser resolutions to improve the correspondence between the location of observations and grid cells.

Although the choice of remote sensing measurements today is from a wider variety of sensors than at any time in the past, the selection of a sensor for irrigation mapping is still primarily dictated by the geographic range of the study. For large areas such as continents, the primary sources of data have typically been coarse resolution sensors such as AVHRR, MODIS, MERIS, and SPOT VEGETATION with wide area coverage [24,65-67]. Similarly, data from high spatial resolution sensors like Landsat and SPOT have been used in support of local and regional scale applications that require increased spatial detail. What is less known, however, is the magnitude of errors incurred in irrigated area estimates as a function of the spatial resolutions of different sensors. Previous studies show that while coarsening the spatial resolution clearly leads to a loss of spatial detail [68], the magnitude of errors in area estimation as pixels increase in size is dependent on the spatial structure of the landscape $[69,70]$.

\section{Spectral data requirements}

Remote sensing of irrigated lands over different geographic regions involves significant challenges, first in selecting spectral bands or indices that contain the maximum amount of irrigation-related information, then in relating this information to complex forms of irrigation presence. For instance, 
while satellite-derived indices are extremely useful in detecting vegetated areas in agricultural lands, the cause of spatial and temporal variability in biomass, whether as a result of rainfall or irrigation, is much less straightforward, hence more difficult to determine. A further complication may arise when only supplemental irrigation is practiced [71]. While, the characteristic shape of the fields where center pivot irrigation is practiced is obvious, this visual discrimination is neither evident nor can it easily be incorporated in automated image classification.

To overcome these challenges the characteristic attributes of irrigated lands, especially those characteristics that are observable with remotely sensed measurements must first be identified. One such attribute is related to vegetation "greenness." There is an overwhelming consensus that the NDVI is an important tool to monitor vegetation, including irrigated lands [65,72-75]. Studies of agricultural lands have shown that in many semi-arid regions, NDVI alone is a good indicator of irrigation [30,33,36,37], as well as irrigation status [35], crop condition [76] and large-scale vegetation dynamics [77].

While the NDVI signal associated with irrigation allows identification of irrigated lands, particularly in semi-arid areas characterized by a single irrigation period and simple land cover types, in many areas of the world there are multiple irrigation periods and several crop types with different schedules. In these locations, the NDVI signal associated with irrigation might be more subtle. Frequent observations of the NDVI from sensors like MODIS may help to map these lands and thus determine acquisition times for high spatial resolution imagery. However, difficult cases for distinguishing irrigated from non-irrigated crops occur in locations where the same crop type is grown with and without irrigation during the same growing season. Temporal NDVI profiles of both irrigated and non-irrigated crops in these locations may exhibit an identical pattern. While irrigated fields often exhibit greater greenness due to the constant availability of moisture, the NDVI difference between irrigated and non-irrigated fields is small and probably useless in distinguishing them. Thus, a more sensitive index may be required to make this distinction.

A large body of research of spectral remote sensing of vegetation canopies indicates that moisture stress in vegetation is strongly manifested in spectral indices related to chlorophyll content [78,79]. One such index, suggested by Gitelson et al. [80] to be used with the MODIS sensor, is the Green Index (GI) defined as:

$$
G I=\rho_{\text {nir }} / \rho_{\text {green }}
$$

where $\rho_{\text {green }}$ is the reflectance in the green spectral region. The theoretical foundations of the GI are given in Gitelson et al. [78]. Briefly, it is based on evidence that in the green spectrum (centered around $510 \mathrm{~nm}$ ) the specific absorption coefficient of chlorophylls is very high while green leaves are absorbing more than 80 percent (e.g., [81]). In contrast, depth of light penetration into leaves in the blue and red spectral ranges is one-fourth to one-sixth as much (e.g., [82]). Therefore, in the green spectrum, absorption of light is great enough to provide high sensitivity of the GI to chlorophyll content but much lower than in the blue and red to avoid light saturation [78].

The theoretical foundation for using the GI for irrigation assessment is that irrigated crops with very little or no soil moisture stress will exhibit higher chlorophyll content than non-irrigated crops that potentially experience moisture stress. To test this hypothesis and the sensitivity of the GI to the presence of irrigation (moisture), Ozdogan and Gutman [20] compared four vegetation indices in the 
midwestern US: NDVI, Enhanced Vegetation Index (EVI) [81], Wide Dynamic Range Vegetation Index (WDRVI) [82], and the GI, using the following Relative Sensitivity Index (RSI):

$$
R S I=\frac{I_{\text {irr }}-I_{\text {non }}}{I_{\text {non }}(\max )-I_{\text {non }}(\min )}
$$

In Equation (2), $I_{i r r}$ and $I_{\text {non }}$ are the irrigated and non-irrigated values for each index, I, at each time period, normalized by the seasonal amplitude (maximum-minimum) of non-irrigated values of each index. RSI represents the difference between irrigated and non-irrigated index value compared to the seasonal maximum change non-irrigated value of the same index. Comparison of relative sensitivity of all four indices reveals that the GI shows the greatest sensitivity to irrigation presence during peak crop growth (Figure 3). Similar results were obtained by Gitelson et al. [83] in the same location. Recognizing the increased sensitivity to irrigation, we suggest that future mapping studies include the GI in the classification process.

Figure 3. Sensitivity of four vegetation indices, namely NDVI, EVI, GI, and WDRVI, to irrigation presence as measured by Relative Sensitivity Index (RSI) in Nebraska for 2002. Each index was generated from an average response using a sample of approximately five individual sites. Please see the text for details on the RSI. Adapted from Ozdogan and Gutman [20].

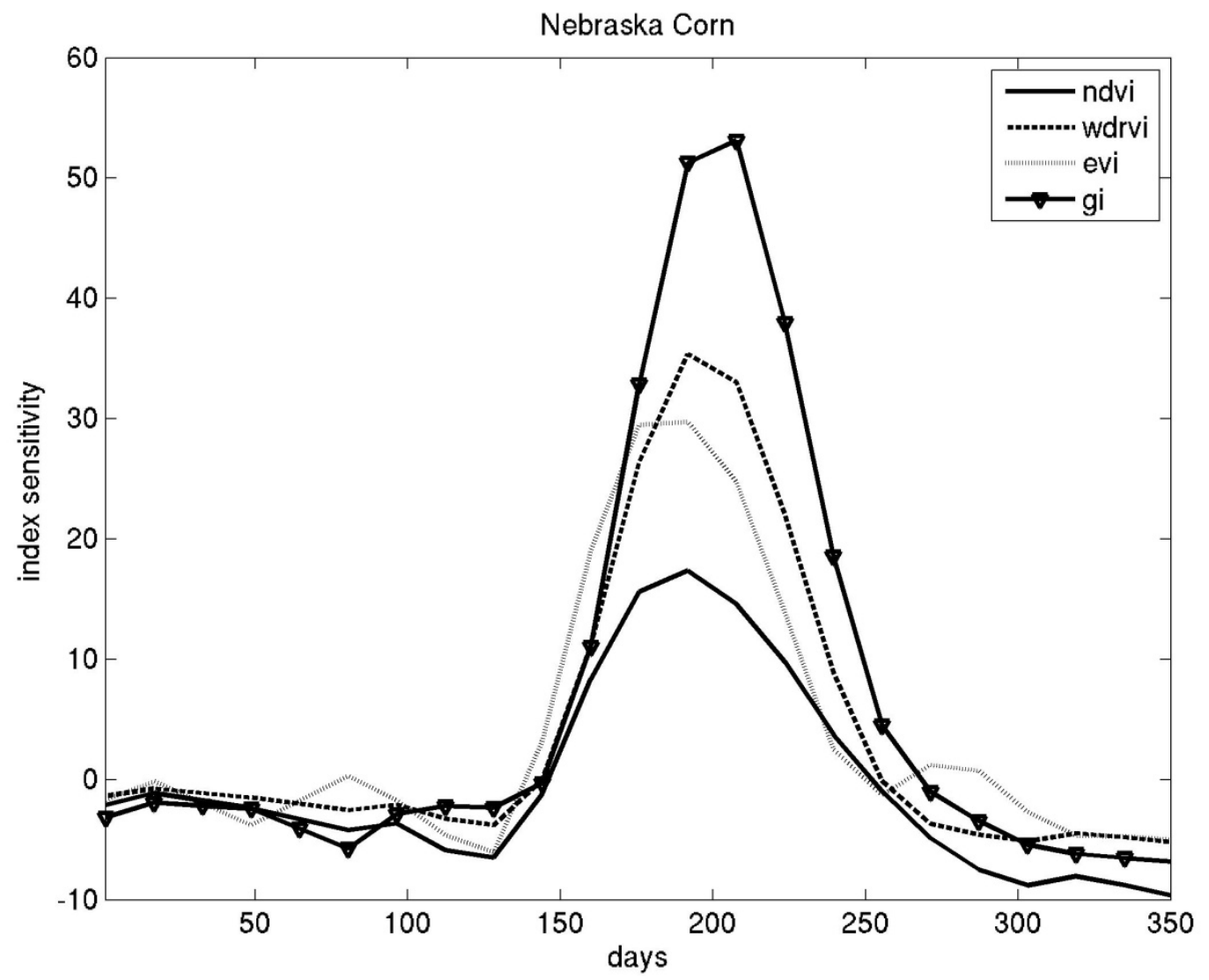

As noted, irrigated areas are very dynamic in time and space and thus their spectral signatures quickly change across the growing seasons. Thenkabail et al. [21] exploited this feature of irrigated areas in a two-dimensional near infrared versus red band spectral reflectivity plots of different land 
cover types including that of irrigation (Figure 4). Typically, classes that have high near-infrared reflectivity and low red reflectivity are forests, agricultural lands and natural vegetation. Classes that occupy bright areas with high near-infrared and high red reflectivity are likely to be open/barren areas, sparse vegetation, dry vegetation, clouds and built-up areas. Classes that occupy wet areas have low near-infrared and low red reflectivity and are likely to be wetlands, moist lands, water bodies, cloud shadows and swamp forests. From irrigation perspective, these two dimensional spectral time curves provide very useful information on class behavior. For example, irrigated areas occupy the largest territory and the two dimensional plots provide very good indications of class temporal and spectral characteristics.

Figure 4. Space-time spiral curves (ST-SCs) in class identification and labeling. The ST-SCs track changes of time series over time and across space. The numbers seen in each class represent Julian date and each class moves around a 'territory' in 2D feature space over time. Adapted from Thenkabail et al. [57].

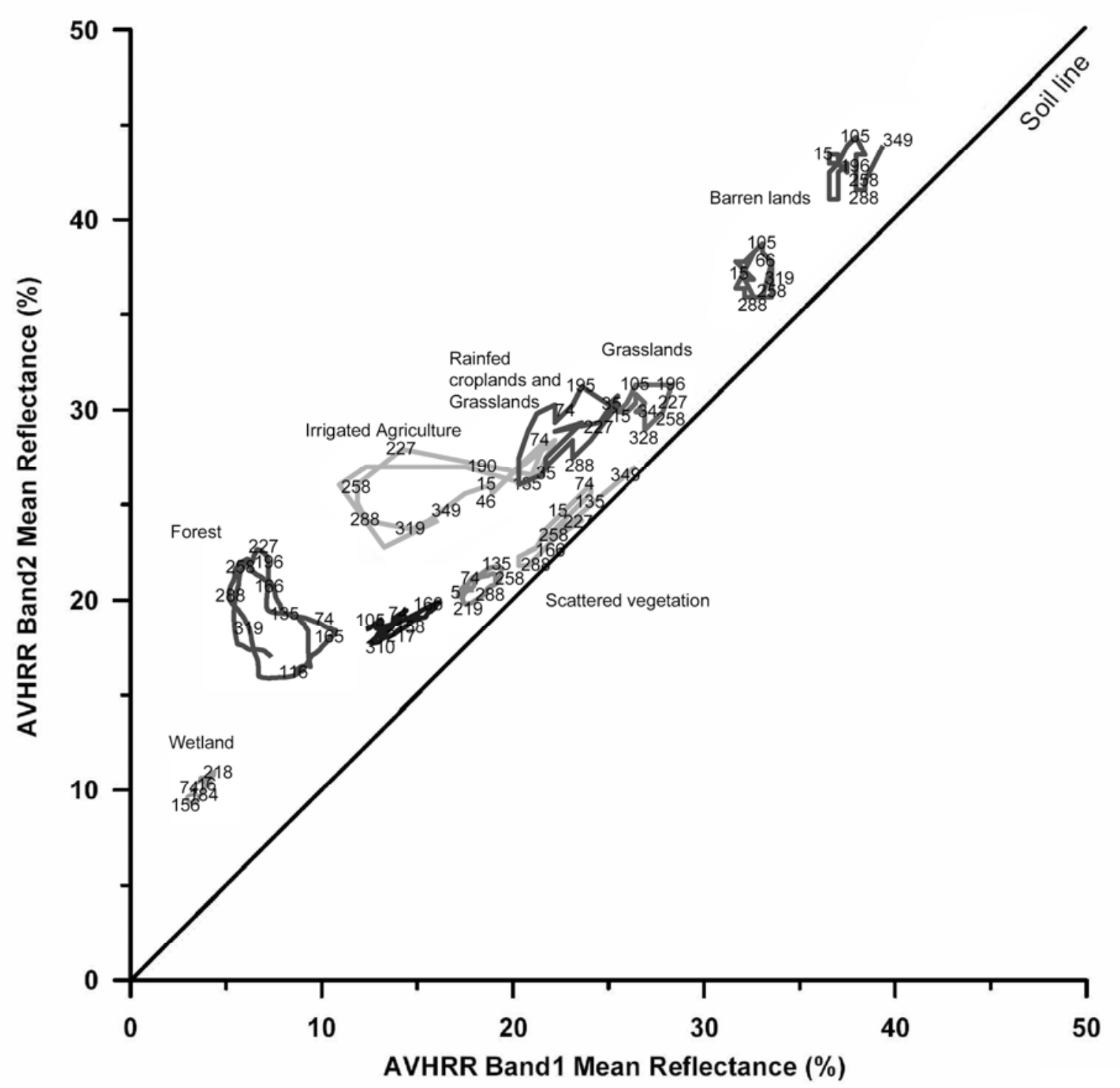

Another approach to spectral identification of irrigation is to compare each pixel's greenness value to its regional mean as measured by an index. Here region is loosely defined and can include a 
command area or an agro-ecological zone, and applies only to the same land cover type (e.g., agriculture). The assumption is that the pixels representing irrigated fields will have greater greenness than their non-irrigated counterparts within any region.

Although it's examples are rare and far in-between in irrigation mapping studies, there is also significant value in considering hyperspectral narrow band indices for further improving our understanding and accurate identification of irrigated areas. Also known as imaging spectroscopy, hyperspectral imaging has been used under laboratory conditions for over 100 years for identification of materials and their composition. Spectroscopy can be used to detect individual absorption features due to specific chemical bonds in a solid, liquid, gas including vegetation. The key to a successful use of narrow band spectrometers in identifying irrigation status of vegetation canopies will be through detection of moisture stress (which is often non-existent in irrigated areas) and through leaf chemical properties that are unique under artifical watering conditions.

\section{Temporal data requirements}

The mapping of irrigated lands with remote sensing is strongly affected by the timing of image acquisition and the number of images used [84]. The image-based monitoring relies heavily on the temporal monitoring of crop evolution during the growing season by means of vegetation indices. Thus, precise timing of image capture is necessary to effectively distinguish irrigated crops from each other and from other land cover types [37]. This requires knowledge of the growth schedules of crop types common to the area. For example, Pax-Lenney et al. [35] concluded that in addition to the number of images needed, timing of those images within the agrarian calendar proved to be more important than expected for lands under continuous cultivation in the Nile delta. In that study, nonproductive lands could not be identified with adequate accuracy by using images from low-growth seasons and their areas were overestimated by at least 400 percent with data sets consisting of two, three, or four low-growth-season images. Thus, even large multi-temporal datasets do not entirely mitigate the effects of timing interactions between images. Timing and image combinations restrict the accuracy of the identification of irrigated lands even with large image data sets. In some locations this is unfortunate, because low vegetation imagery is often the only cloud-free imagery available.

Most studies at local scales show that irrigated area overestimation problems decrease as more peak-season images are incorporated into the data sets. However, given data sets of equal numbers of images, peak-growth imagery may not always perform as well as combinations of peak and low growth-season imagery. The result is that in some cases, incorporating the variability or range of the NDVI values across seasons delineates irrigated from non-irrigated lands more accurately than maximum NDVI data alone can do [35].

These studies also suggest that the number of images needed to achieve a predetermined level of accuracy will differ between geographic regions. This emphasizes the fact that the number of images needed to monitor irrigated lands will vary by location, regional agricultural practices, and the feature of interest.

As stated, the quality of irrigation maps derived from remote sensing partly depends on the number and timing of images used. While there is a need for multi-temporal imagery in distinguishing summer crops, this analysis shows that in the study area, methods such as NDVI thresholding based on single images produces useful results, especially if guided by high frequency remote sensing observations 
like MODIS. This is particularly important for incorporating remote sensing technology into the future irrigation management practices in many of the world's semi arid areas. While remote detection of summer irrigated lands by this means may be simplistic, it provides an excellent example of the practical utility of remote sensing for summer irrigation monitoring.

\section{Areas that Require Further Research}

\section{Use of Radar data}

To form the basis for developing sustainable water management practices requires knowledge of the current extent, area, and the status of irrigated agricultural landscapes. Advances in remote sensing based mapping technologies have partially contributed in documenting and monitoring irrigated land use types. There are, however, several unresolved problems associated with mapping irrigated areas at regional to continental scales in regions with frequent cloud cover. As described in previous sections, optical remote sensing has been successfully used for classification of irrigated areas from local to global scales using visual interpretation and classification as their primary approach for extracting thematic information.

During the past decade, several radar sensors have been deployed in space. Though none were designed specifically for irrigation mapping, several investigations have demonstrated that the data provide unique information about the characteristics of irrigated landscapes [85-87]. First, the radar data can be acquired as frequently as possible without atmospheric interference and solar angle variations. Second, depending on the wavelength, the radar backscatter signal carries information about the moisture status of vegetated landscapes. For example, [85] discovered that the radar backscatter coefficient of rice fields, appears to have a significant temporal variation and that this variation can be used to identfy paddy rice fields. Similarly, [86] report a strong relationship between L-band backscatter and plant growth in manually planted rice areas although the radar response is strongly dependent on parameters related to the spatial distribution of the plants. Despite these artifacts, however, a correlation between plant growth and backscatter has been observed for all fields, independent of plant spacing and field orientation [86]. While these investigations established the physical foundation for understanding the relationship between radar backscatter in paddy rice fields, another study [87] suggests that rice production estimates require at least three radar acquisitions taken at three crop growth and development stages. However, if multi-parameter radar data are available, only two acquisitions may be sufficient.

Note that the combination of radar data together with optical data has not yet been exploited to its fullest extent. Radar is useful because of its sensitivity to soil moisture status, even in complex environments. Furthermore, radar data can be collected in almost all weather conditions, a characteristic that is especially important in areas with frequent cloud cover.

\section{Use of passive microwaves for moisture status}

Irrigated areas, by definition, contain increased soil moisture due to artificial watering of fields. Microwave remote sensing can be used to estimate soil moisture and, by extension, irrigation, on the basis of the large contrast that exists between the dielectric constant values for dry and wet soils $[88,89]$. Temporal monitoring of water availability at the soil root zone during growth periods 
could provide a way to pre-determine irrigated and non-irrigated fields. This information can then be refined using optical or radar sensors at increased spatial resolutions. Because microwaves penetrate clouds, microwave remote sensing also presents a good alternative to optical remote sensing for monitoring irrigation distribution, as well as the health and water needs of irrigated areas in humid locations with frequent cloud cover. One limitation of passive microwave data is their coarse spatial resolution (on the order of $25 \mathrm{~km}$ on a side). Nevertheless, these data can be used to pre-determine the locations of irrigated areas in a broader context using remote sensing.

\section{$\underline{\text { Classification algorithms with many-to-one mapping capabilities }}$}

Because of the number of images to be processed and the need for multi-temporal data, the use of more automated methods based on supervised classification using machine learning algorithms is important. Neural networks (specifically Fuzzy ARTMAP: [90-92]), decision trees [24], and support vector machines (SVM) [93] are particularly powerful in handling information from multiple sources or dates to generate reliable classification results. One of the strengths of these machine-learning algorithms is the "many-to-one" mapping capability, meaning that any given output class can have many spectral manifestations, each of which is preserved internally within the trained set. For irrigation mapping, this is particularly useful, as most studies use only a limited number of classes and the non-irrigated class could encompass multiple land cover classes. The idea of many spectral manifestations can also be extended into the temporal domain, where irrigated productive agricultural fields and barren non-irrigated fields each with particular multi-date NDVI trajectories can be fed into a training set as individual training samples to classify the amount of irrigated land per study period.

\section{$\underline{\text { Object-oriented classification }}$}

When using high spatial resolution data to map irrigated agricultural lands, traditional spectral based methods may result in rather poor or incorrect classification. This is because in this type of data, much information is contained in spatial relations of pixels and not in their spectral response or temporal change. Therefore, methods that exploit the relationship between a group of pixels in an attempt to generate improved classification are promising when analyzing high resolution data in fragmented environments. This form of classification is called the object-oriented approach. Unfortunately, there are no examples of application of object-oriented classification methods to map irrigated landscapes in the literature, although a few examples exist for mapping land cover types in cultivated settings.

In an object-oriented classification process, image objects (e.g., agricultural fields) can be created by means of automatic segmentation algorithms, or by ancillary sources of information such as cadastral cartography. In general, a segmentation algorithm would produce a space division conditioned by sensor attributes instead of geographic characteristics. Image classification by parcels has been widely used for agricultural applications [94,95]. Object-based image analysis can be accomplished following two different approaches: prior to classification (per-parcel) and after per-pixel classification. In the first approach, descriptive features of each parcel are first calculated and then parcels are classified as a whole using any of the available classification algorithms. In the latter approach, the frequency of the classified pixels within each parcel using either the majority pixel class as the assigned pixel label or a mixed label describing the heterogeneity of the parcel assigned [94,96]. 


\section{$\underline{\text { Data Fusion }}$}

Information about the agricultural areas is currently being captured by a number of satellite-based sensors of different spatial, spectral, temporal, and radiometric characteristics. It would be beneficial to utilize information from multiple sources to more effectively map irrigated areas and the concept of merging data for the same scene from different sensors is called data fusion. The motivation behind data fusion is to generate an interpretation of the scene not obtainable with data from a single sensor, or to reduce the uncertainty associated with the data from individual sensors [98]. For example, for an image segmentation or classification task, the goal of fusing data from different sensors is to reduce the classification error rate obtained by single source classification.

Pohl and Van Genderen [98] suggest that before being able to implement and use an image fusion approach some critical questions need to be answered by the user including: What is the objective/application of the user? Which types of data are the most useful for meeting these needs? Which is the 'best' technique of fusing these data types for that particular application? What are the necessary pre-processing steps involved? Which combination of the data is the most successful? These and other questions comprise a large number of parameters to be considered.

While there are not many examples of data fusion for classification problems in irrigated agricultural settings, a small review of the existing methodologies here is useful. In general, data fusion techniques can be grouped into two classes: (i) Colour related techniques, and (ii) Statistical/numerical methods [98]. The first comprises the color composition of three image channels in the RGB color space as well as more sophisticated color transformations. Statistical approaches, on the other hand, are developed on the basis of channel statistics including correlation and filters. Techniques like PCA and regression belong to this group. The numerical methods follow arithmetic operations such as image differencing and ratios but also adding of a channel to other image bands. A form of sophisticated numerical approach uses wavelets in a multiresolution environment. For example, [99] uses this wavelet approach to merge Radar data with information from optical sensors to improve the classification accuracies. The premise here is that while each of these data types are not sufficient in identifying irrigated areas alone, their joint information is powerful and improve classification accuracies [98,99].

In addition to these forms of traditional image fusion methods, there is an emerging trend in the literature of what would be called "information merging" from different satellite sources. The main difference here is the goal of image or information fusion is not to generate pixels with improved information content from multiple data sources but rather to use information from multiple sources to make informed decisions. Some of the best examples of this new form of data fusion are provided by $[7,21,56]$. For example, Ozdogan et al. [7] used information from coarse resolution high temporal frequency observations as a guide to determining the ideal acquisition timing of high spatial resolution data for mapping purposes. While irrigated area mapping was accomplished solely based on high resolution data, the fact that an additional sensor data with different capabilities was used to steer the acquisition times is sufficient to consider this application a form of data fusion. Another great example is provided by [21] who used temporal profiles from one set of observations to interpret land cover type in another sensor data. This form of information fusion is important in irrigated area mapping since the phenology (temporal profiles) of crops are crucial to their identification and mapping-not only from other crops, but also from other vegetation. 
As noted, single date imagery might suffice (if acquired at right time of crop phenology) to map irrigated areas at local scales (e.g., corn vs. soybeans during critical growth phases in U.S. mid-west) but when the extent of mapping in regional/continental/global this will be highly inadequate. Here is where data fusion, along with non-optical data from microwave remote sensing and numerous secondary data, included in data fusion, will be invaluable.

\section{Conclusions}

Satellite data offer tremendous advantages for irrigated area mapping problems at various temporal and spatial scales. However, for more effective use of remote sensing, the analyst should be aware of the limitations and advantages of satellite data and should choose from the available irrigation mapping options accordingly. For example, methods that work in local areas may not lend themselves easily to regional and global applications. Although satellite remote sensing cannot provide the detailed information available from aerial photography or field studies, it can provide complimentary information to these conventional mapping techniques. It can also identify areas where changes are occurring and where more detailed information must be gathered.

Techniques for improving the identification of irrigated areas using remote sensing data include the use of multi-temporal imagery and ancillary data and these methods hold true across all spatial scales considered here. In general, it was found that multi-temporal imagery and ancillary information such as climate, soils, or slope improved irrigation classification. Multi-temporal imagery provides the greatest accuracy for delineating irrigation from other land cover types. While the ideal dates will differ depending on the type and location of irrigation being studied, it is possible to make use of high frequency observations at coarse spatial resolutions even in local area investigations. In general, ancillary data, when available, improves irrigation classification. Machine learning and rule-based classification methods generally provide better results than conventional statistical classification approaches. If detailed information is required at a finer spatial resolution than the satellite sensor can provide, then a subpixel classification scheme should be used. Several methods have been developed for this purpose. In conclusion, mapping of irrigated areas with satellite imagery is difficult but possible. As with many remote sensing problems, satisfactory results may require techniques specific to the location on a case by case basis.

Finally, multisensor data fusion provides an effective paradigm for remote sensing applications by synthesizing data from multiple sensors or sources. For example, high-resolution Landsat style observations can be integrated with low-resolution high temporal frequency observations to complement each other for the improved information extraction in irrigated settings. High spatial resolution images can also be processed by the state-of-the-art image segmentation algorithms to generate individual objects that often correspond to physically meaningful entities, e.g., a cropland unit growing wheat.

\section{Acknowledgements}

This research was partly funded by the NASA Applications Program Grant NNX08AM69G, awarded to Mutlu Ozdogan. The early comments of Annemarie Schneider greatly improved this manuscript. Mutlu Ozdogan is also indebted to the guest editor Prasad Thenkabail for encouraging the 
writing of this review and including it in this special issue. Finally, Elvis Wang at the MDPI editorial office is greatly acknowledged for his meticulous editing that improved the readability of this document.

\section{References and Notes}

1. Gleick, P.H. Global freshwater resources: Soft-path solutions for the 21st century. Science 2003, 302, 1524.

2. Rosegrant, M.W.; Meijer, S.; Cline, S.A. International Model for Policy Analysis of Agricultural Commodities and Trade (IMPACT): Model Description; IFPRI: Washington, DC, USA, 2002.

3. Cai, X.; Rosegrant, M.W. Global water demand and supply projections. Water Int. 2002, 27, 159-169.

4. Stockholm International Water Institute. Available online: http://www.siwi.org/ (accessed on 17 June 2010).

5. Boucher, O.; Myhre, G.; Myhre, A. Direct human influence of irrigation on atmospheric water vapour and climate. Climate Dynamics 2004, 22, 597-603.

6. Gordon, L.J.; Steffen, W.; Jönsson, B.F.; Folke, C.; Falkenmark, M.; Johannessen, A. Human modification of global water vapor flows from the land surface. Proc. Nat. Acad. Sci. USA 2005, 102, 7612.

7. Ozdogan, M.; Woodcock, C.E.; Salvucci, G.D.; Demir, H. Changes in summer irrigated crop area and water use in southeastern Turkey from 1993 to 2002: Implications for current and future water resources. Water Resour. Manag. 2006, 20, 467-488.

8. Wisser, D.; Frolking, S.; Douglas, E.M.; Fekete, B.M.; Vörösmarty, C.J.; Schumann, A.H. Global irrigation water demand: Variability and uncertainties arising from agricultural and climate data sets. Geophys. Res. Lett. 2008, 35, L24408.

9. Alcamo, J.; Döll, P.; Henrichs, T.; Kaspar, F.; Lehner, B.; Rösch, T.; Siebert, S. Global estimates of water withdrawals and availability under current and future "business-as-usual" conditions. Hydrol. Sci. J. 2003, 48, 339-348.

10. Droogers, P.; Aerts, J. Adaptation strategies to climate change and climate variability: A comparative study between seven contrasting river basins. Phys. Chem. Earth, Parts $A / B / C$ 2005, 30, 339-346.

11. Jones, R.N. Analysing the risk of climate change using an irrigation demand model. Climate Res. 2000, 14, 89-100.

12. Rosenzweig, C.; Strzepek, K.M.; Major, D.C.; Iglesias, A.; Yates, D.N.; McCluskey, A.; Hillel, D. Water resources for agriculture in a changing climate: International case studies. Glob. Environ. Change Part A 2004, 14, 345-360.

13. Vörösmarty, C.J.; Green, P.; Salisbury, J.; Lammers, R.B. Global water resources: Vulnerability from climate change and population growth. Science 2000, 289, 284-288.

14. Vörösmarty, C.J.; Sahagian, D. Anthropogenic disturbance of the terrestrial water cycle. BioScience 2000, 50, 753-765.

15. Moore, N.; Rojstaczer, S. Irrigation's influence on precipitation-Texas High Plains, U.S.A. Geophys. Res. Lett. 2002, 29, doi:10.1029/2002GL014940. 
16. Kueppers, L.M.; Snyder, M.A.; Sloan, L.C. Irrigation cooling effect: Regional climate forcing by land-use change. Geophys. Res. Lett. 2007, 34, L03703.

17. Vörösmarty, C.J. Global water assessment and potential contributions from Earth Systems Science. Aqua. Sci.-Res. Across Boundaries 2002, 64, 328-351.

18. Bastiaanssen, W.G.M.; Molden, D.J.; Makin, I.W. Remote sensing for irrigated agriculture: Examples from research and possible applications. Agr. Water Manag. 2000, 46, 137-155.

19. Thenkabail, P.S.; Dheeravath, V.; Biradar, C.M.; Gangalakunta, O.R.P.; Noojipady, P.; Gurappa, C.; Velpuri, M.; Gumma, M.; Li, Y. Irrigated area maps and statistics of India using remote sensing and national statistics. Remote Sensing 2009, 1, 50-67.

20. Ozdogan, M.; Gutman, G. A new methodology to map irrigated areas using multi-temporal MODIS and ancillary data: An application example in the continental US. Remote Sens. Environ. 2008, 112, 3520-3537.

21. Thenkabail, P.S.; Schull, M.; Turral, H. Ganges and Indus river basin land use/land cover (LULC) and irrigated area mapping using continuous streams of MODIS data. Remote Sens. Environ. 2005, 95, 317-341.

22. Loveland, T.R.; Reed, B.C.; Brown, J.F.; Ohlen, D.O.; Zhu, Z.; Yang, L.; Merchant, J.W. Development of a global land cover characteristics database and IGBP DISCover from $1 \mathrm{~km}$ AVHRR data. Int. J. Remote Sens. 2000, 21, 1303-1330.

23. Pittman, K.; Hansen, M.C.; Becker-Reshef, I.; Potapov, P.V.; Justice, C.O. Estimating global cropland extent with multi-year MODIS data. Remote Sensing 2010, 2, 1844-1863.

24. Friedl, M.A.; McIver, D.K.; Hodges, J.C.F.; Zhang, X.Y.; Muchoney, D.; Strahler, A.H.; Woodcock, C.E.; Gopal, S.; Schneider, A.; Cooper, A. Global land cover mapping from MODIS: Algorithms and early results. Remote Sens. Environ. 2002, 83, 287-302.

25. FAO. Topics: Irrigation. Water Development and Management Unit, United Nations Food and Agricultural Organization, Available online: http://www.fao.org/nr/water/topics_irrigation.html (accessed on 17 June 2010).

26. Huston, D.M.; Titus, S.J. An Inventory of Irrigated Lands for Selected Counties within the State of California Based on Landsat and Supporting Aircraft Data; Space Sciences Laboratory Semi-Annual Progress Report; Space Sciences Laboratory Series 16; University of California: Berkeley, CA, USA, 1975; p. 23.

27. Draeger, W.U. Monitoring Irrigated Land Acreage Using Landsat Imagery: An Application Example; USGS Open-file Report No. 76-630; USGS: Sioux Falls, SD, USA, 1976; p. 23.

28. Heller, R.C.; Johnson, K.A. Estimating irrigated land acreage from Landsat imagery. Photogramm. Eng. Remote Sensing 1979, 45, 1379-1386.

29. Thiruvengadachari, S. Satellite sensing of irrigation patterns in semiarid areas-An Indian study. Photogramm. Eng. Remote Sensing 1981, 47, 1493-1499.

30. Kolm, K.E.; Case, H.L. The identification of irrigated crop types and estimation of acreages from Landsat imagery. Photogramm. Eng. Remote Sensing 1984, 50, 1479-1490.

31. Thelin, G.P.; Heimes, F.J. Mapping Irrigated Cropland from Landsat Data for Determination of Water Use from the High Plains Aquifer in Parts of Colorado, Kansas, Nebraska, New Mexico, Oklahoma, South Dakota, Texas, and Wyoming; US Geological Survey Professional Paper; USGS: Washington, DC, USA, 1987. 
32. Rundquist, D.; Hoffman, R.; Carlson, M.; Cook, A. The Nebraska center-pivot inventory-An example of operational satellite remote sensing on a long term basis. Photogramm. Eng. Remote Sensing 1989, 55, 587-590.

33. Eckhardt, D.W.; Verdin, J.P.; Lyford, G.R. Automated update of an irrigated lands GIS using SPOT HRV imagery. Photogramm. Eng. Remote Sensing 1990, 56, 1515-1522.

34. Ram, B.; Kolarkar, A.S. Remote sensing application in monitoring land-use changes in arid Rajasthan. Int. J. Remote Sens. 1993, 14, 3191-3200.

35. Pax-Lenney, M.; Woodcock, C.E.; Collins, J.B.; Hamdi, H. The status of agricultural lands in Egypt: The use of multitemporal NDVI features derived from Landsat TM. Remote Sens. Environ. 1996, 56, 8-20.

36. Abuzar, M.; McAllister, A.; Morris, M. Classification of seasonal images for monitoring irrigated crops in a salinity-affected area of Australia. Int. J. Remote Sens. 2001, 22, 717-726.

37. Beltran, C.M.; Belmonte, A.C. Irrigated crop area estimation using Landsat TM imagery in La Mancha, Spain. Photogramm. Eng. Remote Sensing 2001, 67, 1177-1184.

38. Keene, K.M.; Conley, C.D. Measurement of irrigated acreage in western Kansas from Landsat images. Environ. Geol. 1980, 3, 107-116.

39. Haack, B.; Wolf, J.; English, R. Remote sensing change detection of irrigated agriculture in Afghanistan. Geocarto Int. 1998, 13, 65-75.

40. Rao, P.P.N.; Mohankumar, A. Cropland inventory in the command area of Krishnarajasagar project using satellite data. Int. J. Remote Sens. 1994, 15, 1295-1305.

41. El-Magd, I.A.; Tanton, T.W. Improvements in land use mapping for irrigated agriculture from satellite sensor data using a multi-stage maximum likelihood classification. Int. J. Remote Sens. 2003, 24, 4197-4206.

42. Kauth, R.J.; Thomas, G.S. The tasseled cap: graphic description of the spectral-temporal development of agricultural crops as seen by Landsat. In Proceedings of the Symposium on Machine Processing of Remotely Sensed Data, West Lafayette, IN, USA, June 29-July 1, 1976; pp. 41-51.

43. Manavalan, P.; Kesavasamy, K.; Adiga, S. Irrigated crops monitoring through seasons using digital change detection analysis of IRS-LISS 2 data. Int. J. Remote Sens. 1995, 16, 633-640.

44. Starbuck, M.J.; Tamayo, J. Monitoring vegetation change in Abu Dhabi Emirate from 1996 to 2000 and 2004 using Landsat satellite imagery. Arab Gulf J. Scientific Res. 2007, 25, 71-80.

45. Simonneaux, V.; Duchemin, B.; Helson, D.; Raki, E.; Olioso, A.; Chehbouni, A. The use of high-resolution image time series for crop classification and evapotranspiration estimate over an irrigated area in central Morocco. Int. J. Remote Sens. 2008, 29, 95-116.

46. Akbari, M.; Mamanpoush, A.; Gieske, A.; Miranzadeh, M.; Torabi, M.; Salemi, H.R. Crop and land cover classification in Iran using Landsat 7 imagery. Int. J. Remote Sens. 2006, 27, 4117-4135.

47. Toomanian, N.; Gieske, A.S.M.; Akbary, M. Irrigated area determination by NOAA-Landsat upscaling techniques, Zayandeh River Basin, Isfahan, Iran. Int. J. Remote Sens. 2004, 25, 4945-4960. 
48. Xiao, X.; Boles, S.; Liu, J.; Zhuang, D.; Frolking, S.; Li, C.; Salas, W.; Moore Iii, B. Mapping paddy rice agriculture in southern China using multi-temporal MODIS images. Remote Sens. Environ. 2005, 95, 480-492.

49. Biggs, T.W.; Thenkabail, P.S.; Gumma, M.K.; Scott, C.A.; Parthasaradhi, G.R.; Turral, H.N. Irrigated area mapping in heterogeneous landscapes with MODIS time series, ground truth and census data, Krishna Basin, India. Int. J. Remote Sens. 2006, 27, 4245-4266.

50. Alexandridis, T.K.; Zalidis, G.C.; Silleos, N.G. Mapping irrigated area in Mediterranean basins using low cost satellite Earth Observation. Comput. Electron. Agr. 2008, 64, 93-103.

51. Wardlow, B.D.; Egbert, S.L. Large-area crop mapping using time-series MODIS $250 \mathrm{~m}$ NDVI data: An assessment for the US Central Great Plains. Remote Sens. Environ. 2008, 112, 1096-1116.

52. Dheeravath, V.; Thenkabail, P.S.; Chandrakantha, G.; Noojipady, P.; Reddy, G.P.O.; Biradar, C.M.; Gumma, M.K.; Velpuri, M. Irrigated areas of India derived using MODIS $500 \mathrm{~m}$ time series for the years 2001-2003. ISPRS J. Photogramm. Remote Sens. 2009, 65, 42-59.

53. Kamthonkiat, D.; Honda, K.; Turral, H.; Tripathi, N.K.; Wuwongse, V. Discrimination of irrigated and rainfed rice in a tropical agricultural system using SPOT VEGETATION NDVI and rainfall data. Int. J. Remote Sens. 2005, 26, 2527-2547.

54. FAO. FAOSTAT-PC, FAO Statistics on diskette. Food and Agriculture Organization of the United Nations: Rome, Italy, 1998.

55. Arino, O.; Gross, D.; Ranera, F.; Bourg, L.; Leroy, M.; Bicheron, P.; Latham, J.; Di Gregorio, A.; Brockman, C.; Witt, R. GlobCover: ESA service for global land cover from MERIS. In Proceedings of IEEE International Geoscience and Remote Sensing Symposium, Barcelona, Spain, 23-28 July 2007; pp. 2412-2415.

56. Thenkabail, P.S.; Parthasaradhi, G.; Biggs, T.W.; Gumma, M.K.; Turral, H. Spectral matching techniques to determine historical land use/land cover (LULC) and irrigated areas using time-series AVHRR Pathfinder datasets in the Krishna river basin, India. Photogramm. Eng. Remote Sensing 2007, 73, 1029-1040.

57. Thenkabail, P.S.; Biradar, C.M.; Noojipady, P.; Dheeravath, V.; Li, Y.J.; Velpuri, M.; Gumma, M.; Gangalakuntag, O.R.P.; Turral, H.; Cai, X.L.; Vithanage, J.; Schull, M.A.; Dutta, R. Global irrigated area map (GIAM), derived from remote sensing, for the end of the last millennium. Int. J. Remote Sens. 2009, 30, 3679-3733.

58. Thenkabail, P.S.; Biradar, C.M.; Noojipady, P.; Cai, X.; Dheeravath, V.; Li, Y.; Velpuri, M.; Gumma, M.K.; Pandey, S. Sub-pixel area calculation methods for estimating irrigated areas. Sensors 2007, 7, 2519-2538.

59. Kurz, B.; Seelan, S.K. Use of remote sensing to map irrigated agriculture in areas overlying the Ogallala Aquifer, U.S. In Remote Sensing of Global Croplands for Food Security; Thenkabail, P.S., Turral, H., Lyon, J.G., Biradar, C., Eds.; CRC Press: Boca Raton, FL, USA, 2009.

60. Lobell, D.B.; Asner, G.P.; Ortiz-Monasterio, J.I.; Benning, T.L. Remote sensing of regional crop production in the Yaqui Valley, Mexico: Estimates and uncertainties. Agr. Ecosyst. Environ. 2003, 94, 205-220.

61. Ozdogan, M. Mapping crop types from temporal unmixing of MODIS data: The case for Independent Component Analysis. Remote Sens. Environ. 2010, 114, 1190-1204. 
62. Hutmacher, R.B. Infrared thermometry for canopy temperature measurements: applications and limitation in irrigation scheduling. In Sensor and Techniques for Irrigation Management; California State University: Fresno, CA, USA, 1988; pp. 19-22.

63. Velpuri, N.M.; Thenkabail, P.S.; Gumma, M.K.; Biradar, C.M.; Dheeravath, V.; Noojipady, P.; Yuanjie, L. Influence of Resolution in Irrigated Area Mapping and Area Estimations. Photogramm. Eng. Remote Sensing 2009, 75, 1383-1396.

64. Tan, B.; Woodcock, C.E.; Hu, J.; Zhang, P.; Ozdogan, M.; Huang, D.; Yang, W.; Knyazikhin, Y.; Myneni, R.B. The impact of gridding artifacts on the local spatial properties of MODIS data: Implications for validation, compositing, and band-to-band registration across resolutions. Remote Sens. Environ. 2006, 105, 98-114.

65. De Fries, R.S.; Hansen, M.; Townshend, J.R.G.; Sohlberg, R. Global land cover classifications at $8 \mathrm{~km}$ spatial resolution: the use of training data derived from Landsat imagery in decision tree classifiers. Int. J. Remote Sens. 1998, 19, 3141-3168.

66. Roy, D.P.; Lewis, P.E.; Justice, C.O. Burned area mapping using multi-temporal moderate spatial resolution data-A bi-directional reflectance model-based expectation approach. Remote Sens. Environ. 2002, 83, 263-286.

67. Frolking, S.; Xiao, X.; Zhuang, Y.; Salas, W.; Li, C. Agricultural land-use in China: A comparison of area estimates from ground-based census and satellite-borne remote sensing. Glob. Ecol. Biogeogr. 1999, 8, 407-416.

68. Woodcock, C.E.; Strahler, A.H. The factor of scale in remote sensing. Remote Sens. Environ. 1987, 21, 311-332.

69. Moody, A.; Woodcock, C.E. The influence of scale and the spatial characteristics of landscapes on land-cover mapping using remote sensing. Landscape Ecol. 1995, 10, 363-379.

70. Turner, M.G. Landscape ecology: the effect of pattern on process. Ann. Rev. Ecol. Systemat. 1989, 20, 171-197.

71. Droogers, P. Global Irrigated Area Mapping: Overview and Recommendations; Working Paper 36; International Water Management Institute: Colombo, Sri Lanka, 2002.

72. Goward, S.N.; Markham, B.; Dye, D.G.; Dulaney, W.; Yang, J. Normalized difference vegetation index measurements from the Advanced Very High Resolution Radiometer. Remote Sens. Environ. 1991, 35, 257-277.

73. Justice, C.O.; Townshend, J.R.G.; Holben, B.N.; Tucker, C.J. Analysis of the phenology of global vegetation using meteorological satellite data. Int. J. Remote Sens. 1985, 6, 1271-1318.

74. Myneni, R.B.; Hall, F.G.; Sellers, P.J.; Marshak, A.L. The interpretation of spectral vegetation indexes. IEEE Trans. Geosci. Remote Sens. 1995, 33, 481-486.

75. Tucker, C.J. Red and photographic infrared linear combinations for monitoring vegetation. Remote Sens. Environ. 1979, 8, 127-150.

76. Wiegand, C.L.; Everitt, J.H.; Richardson, A.J. Comparison of multispectral video and SPOT-1 HRV observations for cotton affected by soil salinity. Int. J. Remote Sens. 1992, 13, 1511-1525.

77. Tucker, C.J.; Holben, B.N.; Goff, T.E. Intensive forest clearing in Rondonia, Brazil, as detected by satellite remote sensing. Remote Sens. Environ. 1984, 15, 255-261. 
78. Gitelson, A.A. Relationships between leaf chlorophyll content and spectral reflectance and algorithms for non-destructive chlorophyll assessment in higher plant leaves. J. Plant Physiol. 2003, 160, 271-282.

79. Zarco-Tejada, P.J.; Miller, J.R.; Mohammed, G.H.; Noland, T.L.; Sampson, P.H. Vegetation stress detection through chlorophyll $\mathrm{a}+\mathrm{b}$ estimation and fluorescence effects on hyperspectral imagery. J. Environ. Quality 2002, 31, 1433-1411.

80. Gitelson, A.A.; Vina, A.; Ciganda, V.; Rundquist, D.C.; Arkebauer, T.J. Remote estimation of canopy chlorophyll content in crops. Geophys. Res. Lett 2005, 32, L08403.

81. Gitelson, A.; Merzlyak, M.N. Quantitative estimation of chlorophyll-a using reflectance spectra: experiments with autumn chestnut and maple leaves. J. Photochem. Photobiol. B: Biol. 1994, 22, 247-252.

82. Merzlyak, M.N.; Gitelson, A. Why and what for the leaves are yellow in autumn? On the interpretation of optical spectra of senescing leaves (Acer platanoides L.). J. Plant Physiol. 1995, 145, 315-320.

83. Huete, A.; Justice, C.; Van Leeuwen, W. MODIS vegetation index (MOD13) algorithm theoretical basis document. NASA Goddard Space Flight Centre: Greenbelt, MD, USA, 1999.

84. Pax-Lenney, M.; Woodcock, C.E. The effect of spatial resolution on the ability to monitor the status of agricultural lands. Remote Sens. Environ. 1997, 61, 210-220.

85. Ribbes, F.; Toan, T.L. Rice field mapping and monitoring with RADARSAT data. Int. J. Remote Sens. 1999, 20, 745-765.

86. Rosenqvist, A. Temporal and spatial characteristics of irrigated rice in JERS-1 L-band SAR data. Int. J. Remote Sens. 1999, 20, 1567-1587.

87. Shao, Y.; Fan, X.; Liu, H.; Xiao, J.; Ross, S.; Brisco, B.; Brown, R.; Staples, G. Rice monitoring and production estimation using multitemporal RADARSAT. Remote Sens. Environ. 2001, 76, 310-325.

88. Njoku, E.G.; Wilson, W.J.; Yueh, S.H.; Dinardo, S.J.; Li, F.K.; Jackson, T.J.; Lakshmi, V.; Bolten, J. Observations of soil moisture using a passive and active low-frequency microwave airborne sensor during SGP99. IEEE Trans. Geosci. Remote Sens. 2002, 40, 2659-2673.

89. Lakhankar, T.; Krakauer, N.; Khanbilvardi, R. Applications of microwave remote sensing of soil moisture for agricultural applications. Int. J. Terraspace Sci. Eng. 2009, 2, 81-91.

90. Carpenter, G.A.; Gjaja, M.N.; Gopal, S.; Woodcock, C.E. ART neural networks for remote sensing: vegetation classificationfrom Landsat TM and terrain data. IEEE Trans. Geosci. Remote Sens. 1997, 35, 308-325.

91. Gopal, S.; Woodcock, C.E.; Strahler, A.H. Fuzzy Neural Network Classification of Global Land Cover from a 1 AVHRR Data Set. Remote Sens. Environ. 1999, 67, 230-243.

92. Abuelgasin, A. Change detection using adaptive fuzzy neural networks-Environmental damage assessment after the Gulf War. Remote Sens. Environ. 1999, 70, 208-223.

93. Foody, G.M.; Mathur, A. A relative evaluation of multiclass image classification by support vector machines. IEEE Trans. Geosci. Remote Sens. 2004, 42, 1335-1343.

94. Berberoglu, S.; Lloyd C.D.; Atkinson, P.M.; Curran, P.J. The integration of spectral and textural information using neural networks for land cover mapping in the Mediterranean. Comput. Geosci. 2000, 26, 385-396. 
95. Walter, V. Object-based classification of remote sensing data for change detection. ISPRS $J$. Photogramm. Remote Sens. 2004, 58, 225-238.

96. Aplin, P.; Atkinson, P.M.; Curran, P.J. Fine spatial resolution satellite sensor imagery for land cover mapping in the United Kingdom. Remote Sens. Environ. 1999, 68, 206-216.

97. van Laake, P.; Skutsch, M.; McCall, M.K. A Sourcebook of Methods and Procedures for Monitoring and Reporting Anthropogenic Greenhouse Gas Emissions and Removals Caused by Deforestation, Gains and Losses of Carbon Stocks in Forests Remaining Forests, and Forestation; GOFC-GOLD Report Version COP15-1; GOFC-GOLD Project Office, Natural Resources Canada: Alberta, AB, Canada, p. 197.

98. Pohl, C.; Van Genderen, J.L. Multisensor image fusion in remote sensing: Concepts, methods and applications.Int. J. Remote Sens. 1998, 19, 823-854.

99. Gungor, O.; Shan, J. An optimal fusion approach for optical and SAR images. In Proceedings of the ISPRS Commission VII Mid-term Symposium "Remote Sensing: From Pixels to Processes", Enschede, The Netherlands, 8-11 May 2006; pp. 111-116.

(C) 2010 by the authors; licensee MDPI, Basel, Switzerland. This article is an open access article distributed under the terms and conditions of the Creative Commons Attribution license (http://creativecommons.org/licenses/by/3.0/). 